\title{
Indicadores fisiológicos da interação entre deficit hídrico e acidez do solo em cana-de-açúcar
}

\author{
Samira Domingues Carlin ${ }^{(1)}$ e Durvalina Maria Mathias dos Santos(2)
}

\begin{abstract}
(1)Agência Paulista de Tecnologia dos Agronegócios, Polo Centro-Oeste, Rodovia Leônidas Pacheco Ferreira, Km 304, Caixa Postal 66, CEP 17201-970 Jaú, SP. E-mail: sdcarlin@apta.sp.gov.br (2)Universidade Estadual Paulista, Faculdade de Ciências Agrárias e Veterinárias, Departamento de Biologia Aplicada à Agropecuária, Via de Acesso Prof. Paulo Donato Castellane, Km 5, CEP 14884-900 Jaboticabal, SP. E-mail: dumaria@fcav.unesp.br
\end{abstract}

\begin{abstract}
Resumo - O objetivo deste trabalho foi avaliar os indicadores fisiológicos da interação entre deficit hídrico e acidez do solo em plantas jovens de cana-de-açúcar. As plantas foram submetidas a três tratamentos de disponibilidade hídrica, medidos em percentagem de capacidade de campo (CC) - sem estresse ( $70 \% \mathrm{CC})$, estresse moderado (55\% CC) e estresse severo ( $40 \%$ CC); e três tratamentos de acidez no solo, medidos em termos de saturação por bases $(\mathrm{V})$ - baixa acidez $(\mathrm{V}=55 \%)$, média acidez $(\mathrm{V}=33 \%)$ e alta acidez $(\mathrm{V}=23 \%)$. O experimento foi realizado em casa de vegetação a $29,7 \pm 4,3^{\circ} \mathrm{C}$ e $75 \pm 10 \%$ UR. O delineamento experimental utilizado foi o de blocos ao acaso, em esquema fatorial 3x3, com quatro repetições. Após 60 dias, foram determinados os teores de solutos compatíveis - trealose, glicina betaína e prolina - na folha diagnóstico e o crescimento inicial da parte aérea. Os solutos compatíveis trealose, glicina betaína e prolina são indicadores do efeito da interação dos estresses hídrico e ácido no solo. O acúmulo dos solutos compatíveis nos tecidos foliares das plantas não é capaz de impedir a redução na produção de matéria seca da cana-de-açúcar, resultante do agravamento nas condições de disponibilidade hídrica e de acidez no solo.
\end{abstract}

Termos para indexação: Saccharum, glicina betaína, prolina, solutos compatíveis, toxicidade do alumínio, trealose.

\section{Physiological indicators of the interaction between water deficit and soil acidity in sugarcane}

\begin{abstract}
The aim of this work was to assess the physiological indicators of the interaction between water deficit and soil acidity, in sugarcane. The plants were submitted to three treatments of water availability - no stress ( $70 \%$ of field capacity, FC), moderate stress ( $55 \%$ FC), and extreme stress $(40 \% \mathrm{FC})$; and three acidity treatments - no acidity [base saturation $(\mathrm{V})=55 \%$ ], average acidity $(\mathrm{V}=33 \%)$, and high acidity $(\mathrm{V}=23 \%)$. The experiment was carried out in greenhouse, with $29.7 \pm 4.3^{\circ} \mathrm{C}$ and $75 \pm 10 \% \mathrm{RH}$. The experimental design was in randomized blocks, in $3 \times 3$ factorial arrangement, with four replicates. After 60 days, the contents of compatible solutes - trehalose, glycine betaine and proline - in the diagnostic leaf and the initial growth of shoots were determined. The compatible solutes trehalose, glycine betaine, and proline are indicators of the interaction of water and acidity stresses in the soil. The accumulation of compatible solutes in plant foliar tissues can not prevent sugarcane losses in dry matter production, caused by increasing water deficit and soil acidity.
\end{abstract}

Index terms: Saccharum, glycine betaine, proline, compatible solutes, aluminum toxicity, trehalose.

\section{Introdução}

Os estresses ambientais influenciam o crescimento vegetal e causam menor desempenho da cultura no campo. Seca, luminosidade, temperaturas extremas, salinidade, deficiência mineral e baixo $\mathrm{pH}$ nos solos estão entre os principais fatores que restringem a produtividade agrícola (Ashraf \& Foolad, 2007). Mais do que qualquer outro estresse ambiental, a deficiência hídrica dos solos constitui sério problema mundial (Efeoğlu et al., 2009). Um dos grandes desafios da agricultura, portanto, tem sido aumentar a produtividade das culturas em regiões passíveis de ocorrência de restrição hídrica.

Nas regiões tropicais, além do estresse hídrico causado pelos baixos potenciais de água no solo, é comum a ocorrência de solos ácidos que apresentam alumínio trocável, disponível para absorção pelas plantas. Geralmente, o pH abaixo de 5 promove decomposição das micelas de argila, o que resulta no deslocamento do 
alumínio para a fração trocável ou para a solução do solo (Foy et al., 1978). A toxidez do alumínio atinge 50\% das áreas com potencial agrícola no mundo, seja em solos naturalmente ácidos, seja em solos submetidos ao uso intensivo de fertilizantes amoniacais e chuva ácida (Zhang et al., 2007). No Brasil, a ocorrência de solos ácidos com toxidez de alumínio é bastante comum. Nas plantas, o alumínio provoca, sobretudo, a drástica inibição do alongamento celular da raiz, com redução subsequente do crescimento radicular e da absorção de água (Zheng \& Yang, 2005).

Há interesse crescente da comunidade científica por compreender os mecanismos fisiológicos de resposta das plantas aos diversos estresses abióticos (Ashraf \& Foolad, 2007). O ajuste osmótico é uma das principais respostas das plantas ao estresse hídrico e está correlacionado ao grau de resistência. Neste mecanismo, ocorre a biossíntese e o acúmulo de solutos compatíveis, no vacúolo ou no citosol, com função osmoprotetora, o que mantém o equilíbrio hídrico e preserva a integridade celular de proteínas, enzimas e membranas, para a continuidade das atividades vitais, e constitui uma das estratégias adaptativas vegetais aos múltiplos efeitos causados pelos estresses (Abdul Jaleel et al., 2007). Diversas substâncias possuem função osmoprotetora, em que se destacam a trealose, a glicina betaína e a prolina. A trealose protege membranas e proteínas por conferir resistência à dessecação em células com deficiência hídrica (El-Bashiti et al., 2005). A glicina betaína protege as membranas dos tilacóides, o que mantém a eficiência fotoquímica na fotossíntese (Ashraf \& Foolad, 2007). A prolina atua, principalmente, na estabilização de proteínas e na proteção das membranas contra os efeitos deletérios das espécies reativas de oxigênio (Sharma \& Dubey, 2005). Considerado osmólito-chave para o ajuste osmótico de plantas em condições de estresse hídrico (Nayyar, 2003), a prolina também atua como soluto compatível em plantas sob o efeito interativo da deficiência hídrica e da toxicidade de alumínio no solo (Marin et al., 2006; Marin \& Santos, 2008).

A cana-de-açúcar (Saccharum spp., Poaceae) tem sido cultivada no Brasil desde 1532 (Figueiredo, 2008), e é considerada uma das melhores opções para a produção de energia renovável, com grande importância no cenário agrícola mundial (Souza et al., 2005). Nas últimas décadas, com a expansão do cultivo da cana-de-açúcar no Brasil, os efeitos do deficit hídrico e demais estresses ambientais sobre a produtividade da cana têm se tornado cada vez mais evidentes (Maule et al., 2001).
O objetivo deste trabalho foi avaliar os indicadores fisiológicos da interação entre deficit hídrico e acidez do solo, por meio da avaliação dos teores de solutos compatíveis e do crescimento inicial de plantas jovens de cana-de-açúcar.

\section{Material e Métodos}

O experimento foi realizado de agosto a outubro de 2006, em casa de vegetação, com temperatura de $29,7 \pm 4,3^{\circ} \mathrm{C}$ e $75 \pm 10 \%$ UR, na Faculdade de Ciências Agrárias e Veterinárias, da Universidade Estadual Paulista, Jaboticabal, SP.

Para avaliar o efeito interativo dos estresses hídrico e ácido no solo, foram utilizadas plantas jovens de cana-de-açúcar da cultivar IAC91-5155, considerada resistente à seca (Landell et al., 2004). Os minitoletes de uma gema foram provenientes da Unidade de Pesquisa e Desenvolvimento, da APTA Polo Centro-Oeste, Jaú, SP. Após 24 horas da realização da coleta, os toletes foram plantados em recipientes com capacidade para $0,25 \mathrm{dm}^{3}$, com areia lavada e esterilizada. As mudas originadas da brotação de uma gema foram mantidas em areia estéril, sem qualquer restrição hídrica, durante 30 dias. Após este período, foram selecionadas quanto à sanidade e homogeneidade, e foram transferidas para vasos de plástico de $12 \mathrm{dm}^{3}$, preenchidos com Latossolo Vermelho distrófico álico, retirado da camada com 20-40 cm de profundidade, cuja análise química apresentou os seguintes resultados: $\mathrm{pH}\left(\mathrm{CaCl}_{2}\right), 4,1$; matéria orgânica, $14 \mathrm{~g} \mathrm{dm}^{-3} ; \mathrm{P}$ (resina), $4 \mathrm{mg} \mathrm{dm}^{-3}, \mathrm{~K}$, 1,4 $\mathrm{mmol}_{\mathrm{c}} \mathrm{dm}^{-3}$; Ca, $3 \mathrm{mmol}_{\mathrm{c}} \mathrm{dm}^{-3} ; \mathrm{Mg}, 2 \mathrm{mmol}_{\mathrm{c}} \mathrm{dm}^{-3}$; $\mathrm{H}+\mathrm{Al}, 42 \mathrm{mmol}_{\mathrm{c}} \mathrm{dm}^{-3}$; soma de bases (SB), 6,4 mmol $_{\mathrm{c}}$ $\mathrm{dm}^{-3}$; CTC, 48,4 $\mathrm{mmol}_{\mathrm{c}} \mathrm{dm}^{-3}$; saturação por bases (V\%), 13. A análise granulométrica indicou solo de textura argilosa.

$\mathrm{O}$ delineamento experimental utilizado foi o de blocos ao acaso, em esquema fatorial $3 \times 3$, com três tratamentos de disponibilidade hídrica e três tratamentos de acidez do solo, com quatro repetições. Os dados foram submetidos à análise de variância pelo teste $\mathrm{F}$ e à análise de regressão polinomial (Banzatto \& Kronka, 2006).

Os tratamentos de disponibilidade hídrica foram determinados a partir dos valores de microporosidade, obtidos pelo método da mesa de tensão com coluna de água de $60 \mathrm{~cm}$ de altura, considerando-se a densidade do solo, obtida pela relação entre a massa do solo seco em estufa a $110^{\circ} \mathrm{C}$, durante 24 horas, e 
o volume de amostra de solo indeformada (Claessen, 1997). A microporosidade correspondeu a $100 \%$ da capacidade de campo (CC), equivalente a $2,7 \mathrm{~L}$ de água. No entanto, a capacidade de campo do solo foi estabelecida em $70 \%$ da microporosidade, considerada adequada para a maioria das plantas cultivadas. A quantidade de água a ser adicionada foi calculada para cada tratamento de disponibilidade hídrica: sem estresse ( $70 \% \mathrm{CC}, 1,89 \mathrm{~L})$, estresse moderado (55\% CC, 1,49 L) e estresse severo (40\% CC, 1,08 L). Os vasos umedecidos de acordo com os respectivos tratamentos constituíram as unidades experimentais formadas por uma única muda de cana-de-açúcar. $\mathrm{O}$ controle da disponibilidade hídrica foi realizado a cada dois dias, por meio da pesagem dos vasos, tendo-se utilizado balança digital com capacidade máxima de $25 \mathrm{~kg}$ e precisão de $\pm 0,005 \mathrm{~kg}$; a reposição da água evapotranspirada foi realizada sempre que a variação entre a massa inicial do vaso e a massa obtida no dia da avaliação foi igual ou superior a $2 \%$, assim a diferença entre as massas correspondeu à quantidade de água a ser completada (Marin, 2003).

Consideraram-se três níveis de acidez no solo: baixa acidez $\left(\mathrm{V}=55 \%, \mathrm{pH}\left(\mathrm{Cacl}_{2}\right)\right.$ de 5,1 e $0 \mathrm{mmol}_{\mathrm{c}} \mathrm{dm}^{-3}$ de $\left.\mathrm{Al}^{3+}\right)$, média acidez $\left(\mathrm{V}=33 \%\right.$, $\mathrm{pH}\left(\mathrm{Cacl}_{2}\right)$ de 4,6 e $\left.3 \mathrm{mmol}_{\mathrm{c}} \mathrm{dm}^{-3} \mathrm{deAl}^{3+}\right)$ e alta acidez $\left(\mathrm{V}=23 \%, \mathrm{pH}\left(\mathrm{Cacl}_{2}\right)\right.$ de 4,2 e $6 \mathrm{mmol}_{\mathrm{c}} \mathrm{dm}^{-3} \mathrm{de} \mathrm{Al}^{3+}$ ). Para o estabelecimento dos tratamentos de acidez, foram utilizados, como referência, os valores da saturação por bases (V\%) presentes em Raij et al. (1997): baixa acidez (51 a $70 \%)$, média acidez (26 a 50\%) e alta acidez ( 0 a $25 \%)$. O tratamento de baixa acidez ( $\mathrm{V}=55 \%)$ foi estabelecido por ser próximo ao valor de saturação por bases de $60 \%$, que proporciona adequada produtividade para a cultura da cana-de-açúcar (Rossetto et al., 2004). A calagem foi realizada com uso de calcário calcinado $(\mathrm{PRNT}=130 \%)$. Para a homogeneização do calcário calcinado, as amostras de terra foram individualmente acondicionadas em sacos de plástico e, em seguida, foi adicionada água até a capacidade de campo. Essas amostras permaneceram em repouso durante 30 dias. Ao final deste período, amostras de cada tratamento foram submetidas à análise química, para verificação dos níveis de acidez e das concentrações de alumínio tóxico. Aos 60 dias, sob efeito interativo dos estresses, foi quantificado o crescimento da parte aérea, mediante as avaliações do número de folhas, massa de matéria seca de folhas, massa de matéria seca de colmos e área foliar, determinada por meio do sistema de análise de imagens Delta-T Devices LTD., pelo programa Delta-T Image Analysis System. A determinação dos solutos compatíveis trealose, glicina betaína e prolina foi realizada na folha diagnóstico (ou folha +1 ), que é ideal para a avaliação de compostos bioquímicos. A folha diagnóstico em cana-de-açúcar é considerada por Dillewijn (1952) como a primeira folha completamente expandida a partir do ápice, com aurícula visível ("dewlap").

Para a determinação da trealose, utilizou-se o método enzimático de Neves et al. (1994), adaptado por Queiroz (2006), em $1 \mathrm{~g}$ de massa de matéria fresca foliar. A quantificação de glicina betaína foi realizada em $0,5 \mathrm{~g}$ de massa de matéria seca foliar (Grieve \& Grattan, 1983). O teor de prolina foi determinado em $0,5 \mathrm{~g}$ de massa de matéria fresca foliar (Bates et al., 1973).

\section{Resultados e Discussão}

Verificou-se efeito significativo dos tratamentos sobre todas as variáveis avaliadas (Tabela 1, Figuras 1 e 2). Os teores dos solutos compatíveis apresentaram comportamento distinto com a diminuição da disponibilidade hídrica e com o aumento da acidez no solo. Em condições de acidez moderada ( $\mathrm{V}=33 \%)$, a intensificação do estresse hídrico no solo causou diminuição nos teores de trealose até $54,6 \%$ CC. Já em condições de elevada

Tabela 1. Quadrados médios da análise de variância dos efeitos da disponibilidade hídrica e da acidez do solo sobre os teores de solutos compatíveis ${ }^{(1)}$, produção de massa de matéria seca (MS) e crescimento inicial da cultivar de cana-de-açúcar IAC91-5155.

\begin{tabular}{lrccccccc}
\hline Fonte de variação & GL & Trealose & Glicina betaína & Prolina & MS de folhas & MS de colmos & Número de folhas & Área foliar \\
\hline Disponibilidade hídrica (H) & 2 & $5,2691^{* *}$ & $8,5710^{* *}$ & & $0,0193^{* *}$ & $230,0145^{* *}$ & $82,5627^{* *}$ & $23,0278^{* *}$ \\
Acidez (A) & 2 & $2,0434^{* *}$ & $2,0272^{* *}$ & $0,0562^{* *}$ & $1,0235^{\text {ns }}$ & $12,8294^{* *}$ & $0,3611^{\text {ns }}$ \\
Interação HxA & 4 & $1,2562^{* *}$ & $0,9711^{* *}$ & $0,0021^{*}$ & $1,3103^{*}$ & $0,9888^{* *}$ & $0,3652^{\text {ns }}$ \\
Blocos & 3 & $0,0579^{\text {ns }}$ & $0,0888^{\text {ns }}$ & $0,0031^{*}$ & $0,2366^{\text {ns }}$ & $0,1483^{\text {ns }}$ & $0,3981^{\text {ns }}$ \\
Resíduo & 24 & 0,0385 & 0,1077 & 0,0007 & 0,3970 & 0,2164 & $0,6029^{\text {ns }}$ \\
CV $(\%)$ & & 7,2180 & 3,3767 & 4,0723 & 7,8948 & 7,3007 & 0,2315 \\
\hline
\end{tabular}

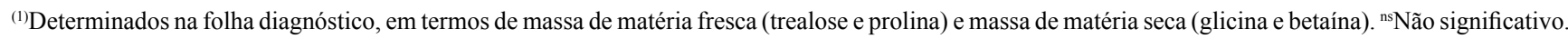
* e **Significativo a 5 e $1 \%$ de probabilidade pelo teste F, respectivamente. GL, graus de liberdade; CV, coeficiente de variação. 
- $\mathrm{V} \%=55 \quad \mathrm{y}=3,288-0,018 \mathrm{x}$

$R^{2}=0,9339$
$V \%=33 \quad y=28,911-0,983 x+0,009 x^{2}$

$$
\mathrm{R}^{2}=1,0000
$$

$\triangle \mathrm{V} \%=23 \quad \mathrm{y}=18,497-0,582 \mathrm{x}+0,005 \mathrm{x}^{2}$

$\mathrm{R}^{2}=1,0000$

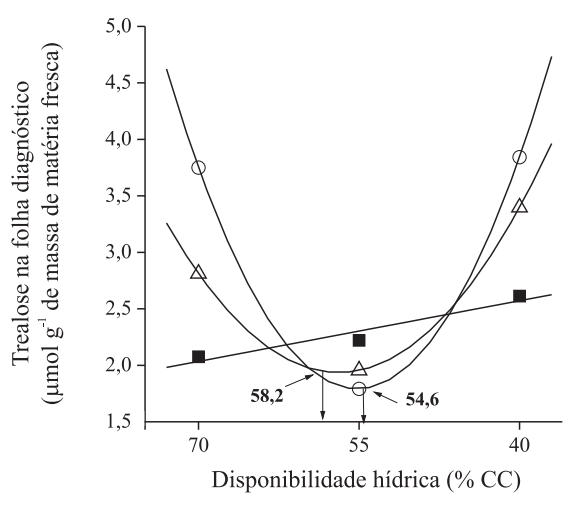

- $\mathrm{V} \%=55 \quad \mathrm{y}=11,819-0,047 \mathrm{x}$

$$
\mathrm{R}^{2}=0,7573
$$

○ $\mathrm{V} \%=33 \quad \mathrm{y}=14,244-0,078 \mathrm{x}$

$\triangle \quad \mathrm{V} \%=23 \quad \mathrm{y}=12,365-0,044 \mathrm{x}$

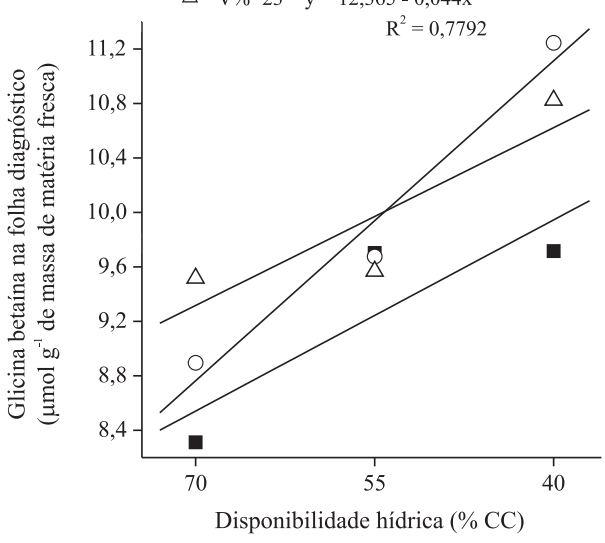

- $\mathrm{V} \%=55 \quad \mathrm{y}=0,8675-0,0030 \mathrm{x}$

$\mathrm{R}^{2}=0,8216$

○ $\mathrm{V} \%=33 \quad \mathrm{y}=1,61733-0,0384 \mathrm{x}+0,0003 \mathrm{x}^{2}$

$$
\mathrm{R}^{2}=1,0000
$$

$\triangle \quad \mathrm{V} \%=23 \quad \mathrm{y}=0,7205-0,00183 \mathrm{x}$

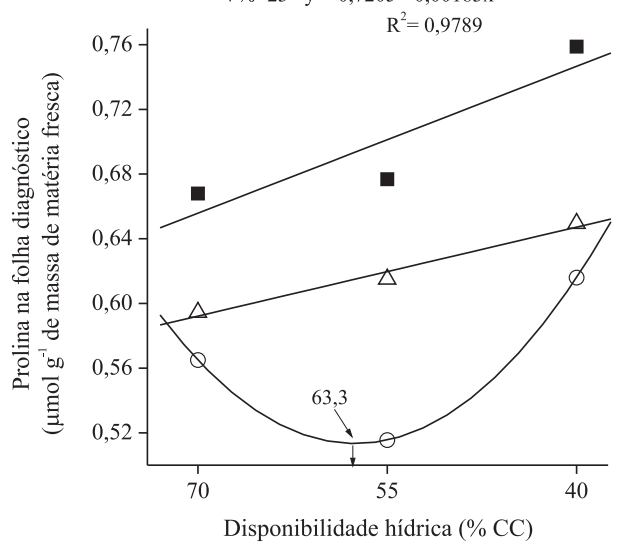

- $70 \% \mathrm{CC} \quad \mathrm{y}=-3,378+0,391 \mathrm{x}-0,005 \mathrm{x}^{2}$ $\mathrm{R}^{2}=1,0000$

- $55 \% \mathrm{CC} \quad \mathrm{y}=3,177-0,079 \mathrm{x}+0,001 \mathrm{x}^{2}$ $\mathrm{R}^{2}=1,0000$

$\triangle 40 \% \mathrm{CC} \quad \mathrm{y}=-0,003+0,220 \mathrm{x}-0,003 \mathrm{x}^{2}$

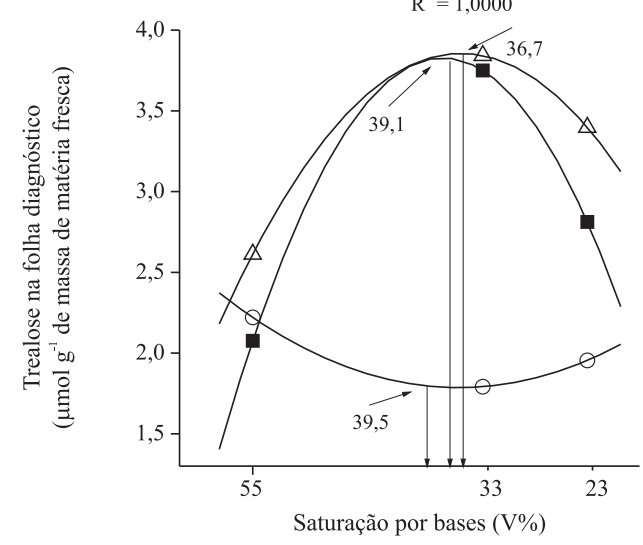

- $70 \% \mathrm{CC} \mathrm{y}=10,2366-0,0358 \mathrm{x}$ $\mathrm{R}^{2}=0,9485$

$\triangle \quad 40 \%$ CC $\mathrm{y}=7,2049+0,2376 \mathrm{x}-0,0034 \mathrm{x}^{2}$ $\mathrm{R}^{2}=1,0000$

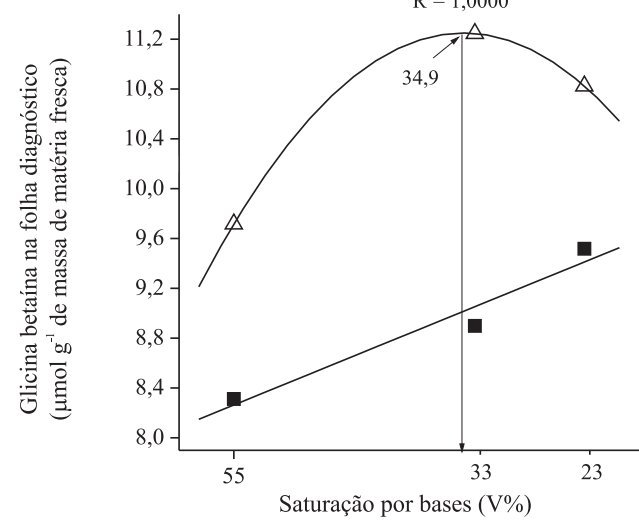

- $70 \%$ CC $y=0,843-0,016 x+0,0002 x^{2}$

$\mathrm{R}^{2}=1,0000$

- $55 \%$ CC $\quad y=1,259-0,041 x+0,0005 x^{2}$ $\mathrm{R}^{2}=1,0000$

$\triangle 40 \% \mathrm{CC} \quad \mathrm{y}=0,960-0,021 \mathrm{x}+0,0003 \mathrm{x}^{2}$

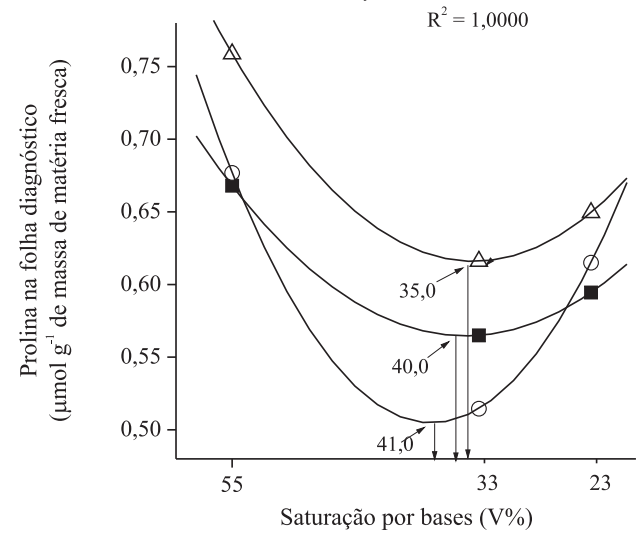

Figura 1. Teores de trealose, glicina betaína e prolina aos 90 dias, em plantas jovens da cultivar de cana-de-açúcar IAC91-5155, sob efeito da interação dos estresses hídrico e ácido no solo, após 60 dias sob efeito interativo dos tratamentos. 

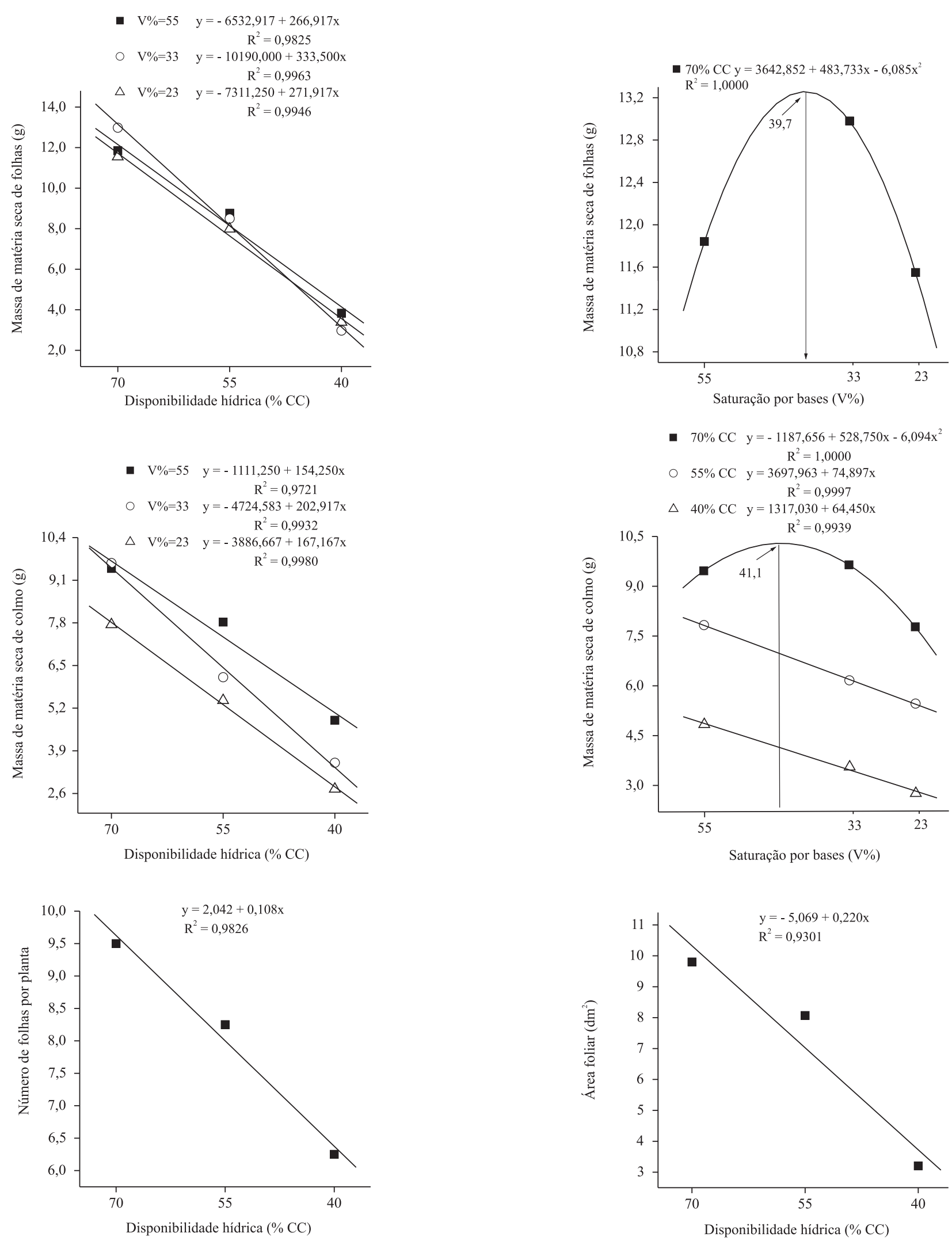

Figura 2. Características relacionadas ao crescimento de plantas de cana-de-açúcar submetidas à redução de disponibilidade hídrica e ao aumento de acidez do solo.

Pesq. agropec. bras., Brasília, v.44, n.9, p.1106-1113, set. 2009 
acidez $(\mathrm{V}=23 \%)$, a redução nos teores desse soluto ocorreu até $58,2 \%$ CC. A partir de então, à medida em que a deficiência hídrica no solo foi intensificada, nos tratamentos de média e alta acidez, observou-se aumento de trealose correspondente a $114,4 \%\left(2,1 \mu \mathrm{mol} \mathrm{g}^{-1}\right) \mathrm{e}$ $73,9 \%\left(1,44 \mu \mathrm{mol} \mathrm{g}^{-1}\right)$, respectivamente. Queiroz (2006) constatou acentuado acúmulo de trealose $(61,4 \%)$ na mesma cultivar de cana-de-açúcar, quando submetida à deficiência hídrica, e o grau de resistência à seca desta planta foi correlacionado à quantidade de trealose acumulada nos tecidos. Outras cultivares de gramíneas resistentes à seca apresentam maior acúmulo de trealose conforme o aumento da deficiência hídrica no solo (Garg et al., 2002; El-Bashiti et al., 2005). No entanto, para o tratamento com baixa acidez, houve aumento de $25,9 \%$ no conteúdo de trealose $\left(0,54 \mu \mathrm{mol} \mathrm{g}^{-1}\right)$, com o aumento da deficiência hídrica no solo.

No tratamento sem restrição hídrica $(70 \% \mathrm{CC})$, a cultivar estudada apresentou significativo acúmulo de trealose $\left(80,7 \%, 1,67 \mu \mathrm{mol} \mathrm{\textrm {g } ^ { - 1 } )}\right.$ até a saturação de bases de $39,1 \%$, o que evidencia que, em condições de estresse moderado de alumínio, ocorre incremento deste dissacarídeo (Figura 1). No entanto, quando a planta foi submetida à elevada toxicidade do alumínio e a um aumento na restrição hídrica $(40 \% \mathrm{CC})$, houve redução de $11,6 \%$ nos teores de trealose $\left.(0,44 \mu \mathrm{mol} \mathrm{g})^{-1}\right)$. Em folhas de milho submetido à toxidez de alumínio, Giannakoula et al. (2008) observaram aumento de $41 \%$ no conteúdo de carboidratos, os quais atuam como solutos compatíveis.

Observou-se acúmulo de 26,4\% nos teores de

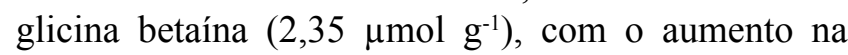
restrição hídrica, no tratamento de média acidez $(\mathrm{V}=33 \%)$. Nas plantas submetidas à alta acidez $(\mathrm{V}$ $=23 \%$ ), houve menor acúmulo de glicina betaína $\left(13,1 \%, 1,26 \mu \mathrm{mol} \mathrm{g}^{-1}\right)$. Em plantas jovens de arroz, em condições de toxidez de alumínio, Sharma \& Dubey (2005) observaram aumento significativo nos teores de glicina betaína. Em contrapartida, no tratamento isento de íons de alumínio na solução do solo $(\mathrm{V}=55 \%)$, houve acúmulo desse soluto de $16,9 \%\left(1,4 \mu \mathrm{mol} \mathrm{g}^{-1}\right)$ com o aumento da deficiência hídrica. Verificou-se que, no tratamento sem restrição hídrica $(70 \% \mathrm{CC})$, houve acúmulo de glicina betaína de $12,7 \%$ com o aumento da acidez no solo. Para o tratamento com maior deficit hídrico $(40 \%$ CC), houve acúmulo de glicina betaína

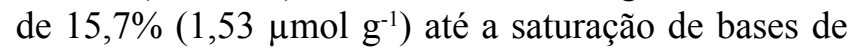
$34,9 \%$. A partir deste valor, notou-se declínio de 3,7\% $\left(0,42 \mu \mathrm{mol} \mathrm{g}^{-1}\right)$ nos teores do soluto. Esses resultados são uma indicação de que a glicina betaína contribui para o ajuste osmótico em plantas jovens de cana-de-açúcar, sob o efeito interativo dos estresses moderados de acidez $(\mathrm{V}=55 \%$ a $\mathrm{V}=34,9 \%)$, em solos com baixo potencial hídrico. O tratamento de disponibilidade hídrica de 55\% CC não apresentou efeito significativo sobre os teores desse soluto, com o aumento da acidez no solo.

Para prolina, observou-se que a intensificação do estresse hídrico, em condições de acidez média no solo $(\mathrm{V}=33 \%)$, causou diminuição de $8,8 \%\left(0,05 \mu \mathrm{mol} \mathrm{g}^{-1}\right)$ nos teores deste soluto até $63,3 \% \mathrm{CC}$ (Figura 1). Contudo, a partir desses valores de disponibilidade hídrica, houve acúmulo de $19,5 \%\left(0,1 \mu \mathrm{mol} \mathrm{g}^{-1}\right)$ de prolina. No tratamento de alta acidez $(\mathrm{V}=23 \%)$, a diminuição da disponibilidade hídrica resultou no incremento de 9,3\% $\left(0,06 \mu \mathrm{mol} \mathrm{g}^{-1}\right)$ no conteúdo de prolina. Isso indica que o aumento da concentração de alumínio no solo pode ter prejudicado a absorção de água pelas plantas, o que teria causado um maior estresse hídrico. Na ausência de alumínio trocável $(\mathrm{V}=55 \%$ ), o aumento da deficiência hídrica resultou em aumento de $13,6 \%\left(0,08 \mu \mathrm{mol} \mathrm{g}^{-1}\right)$ nos teores de prolina, o que mostra que o acúmulo deste aminoácido nas plantas está mais relacionado com a quantidade de água disponível no solo do que com a presença do íon tóxico. Bidóia et al. (2006) constataram acúmulo de prolina, em cana-de-açúcar, de aproximadamente 151,3\%, com o aumento da deficiência hídrica no solo. Em cultivares de milho sob condições de deficiência hídrica, Efeoğlu et al. (2009) observaram significativo aumento nos teores de prolina, porém, quando as plantas foram reidratadas, verificou-se redução nos teores do aminoácido. No ajuste osmótico de folhas com baixo potencial hídrico, a prolina se acumula como soluto compatível para estabilizar membranas e manter a conformação de proteínas, o que impede a desidratação do citosol (Kishor et al., 2005). Existem relatos que consideram a prolina como o principal soluto compatível em plantas sob condições de deficiência hídrica (Nayyar, 2003; Abdul Jaleel et al., 2007; Ashraf \& Foolad, 2007). No entanto, a função da prolina na resposta ao estresse hídrico é questionada. Em plantas superiores, o acúmulo de prolina pode estar relacionado à síntese "de novo" e à diminuição de seu catabolismo. Porém, a baixa utilização de prolina durante o estresse, em consequência da redução na síntese proteica e do aumento na proteólise, também pode contribuir para seu acúmulo (Brito et al., 2008). Esses autores enfatizaram que toda a controvérsia em torno da função da prolina pode refletir a predominância de sua ação em outros mecanismos de resistência que não o ajuste osmótico.

Ao se considerarem os níveis de acidez dentro de cada tratamento de disponibilidade hídrica, observa-se que, 
no tratamento de $55 \% \mathrm{CC}$, houve incremento de $19,1 \%$ $\left(0,1 \mu \mathrm{mol} \mathrm{g}^{-1}\right)$ nos teores de prolina a partir de $\mathrm{V}=41 \%$ (Figura 1). Com a intensificação do deficit hídrico ( $40 \% \mathrm{CC})$, houve aumento de 5,4\% $\left(0,03 \mu \mathrm{mol} \mathrm{g}^{-1}\right)$ no conteúdo de prolina, a partir do $\mathrm{V}=35 \%$. É interessante notar o efeito isolado do alumínio nas plantas jovens de cana-de-açúcar. Na disponibilidade hídrica de 70\% CC, observou-se acúmulo de 5,2\% $\left(0,03 \mu \mathrm{mol} \mathrm{g}^{-1}\right)$ de prolina, a partir do tratamento de média acidez, o que indica que este aminoácido, além de ser considerado osmólito-chave do ajuste osmótico (Nayyar, 2003), também está fortemente relacionado ao estresse por alumínio, o que está de acordo com os dados de Marin \& Santos (2008). Em plantas de guandu, Marin et al. (2006) observaram efeitos significativos da acidez, em condições de disponibilidade hídrica severa $(20 \%$ CC). Sob condições de elevada toxicidade de alumínio, Giannakoula et al. (2008) observaram incremento significativo de prolina em plantas de milho.

$\mathrm{O}$ acúmulo dos solutos compatíveis trealose, glicina betaína e prolina não foi capaz de impedir a redução no crescimento da cultivar de cana-de-açúcar IAC91-5155, pelo aumento da acidez e redução da disponibilidade hídrica no solo. O ajuste osmótico protege o metabolismo das plantas sob condições adversas e, portanto, pode auxiliar na capacitação da planta em tolerar breves períodos de estresse; contudo, não tem efeito direto sobre a produtividade (Serraj \& Sinclair, 2002).

O crescimento das plantas foi drasticamente reduzido pelos estresses hídrico e ácido (Tabela 1, Figura 2). Houve redução no crescimento de folhas e de colmos de 71,8\% e $58,9 \%$, respectivamente, nas condições mais severas de disponibilidade hídrica e acidez do solo. O agravamento dos efeitos da deficiência hídrica, pelo aumento da acidez do solo, deve estar relacionado a alterações provocadas pelo alumínio no sistema radicular, o que pode resultar em menor capacidade de absorção da água e absorção dos nutrientes do solo pelas plantas (Zheng \& Yang, 2005; Zhang et al., 2007). Entretanto, no solo sem deficiência hídrica (70\% CC), o aumento na acidez do solo resultou em diminuição menos acentuada, de apenas $11 \%$.

Oaumento da acidez do solo nãoteve efeito significativo sobre o número de folhas por planta. Contudo, a deficiência hídrica reduziu o número de folhas em 34,2\% e a área foliar em $67,3 \%$ (Figura 2). Quanto menor o número de folhas, menor será a área foliar, o que reflete diretamente sobre a produtividade das culturas (Oliveira et al., 2004). Em plantas jovens de milho sob deficiência hídrica, Efeoğlu et al. (2009) observaram significativa inibição do crescimento, em comparação aos tratamentos sem restrição hídrica.

\section{Conclusões}

1. Em plantas jovens da cultivar de cana-de-açúcar IAC91-5155, os solutos compatíveis trealose, glicina betaína e prolina são indicadores do efeito da interação dos estresses hídrico e ácido no solo.

2. O acúmulo dos solutos compatíveis nas plantas não é capaz de impedir a redução na produção de matéria seca em cana-de-açúcar, resultante do agravamento nas condições de disponibilidade hídrica e de acidez no solo.

\section{Agradecimentos}

Aos professores José Frederico Centurion, Willian Natale e Antonio Orlando di Mauro, pelo auxílio na montagem do experimento; ao professor David Ariovaldo Banzatto, pelo auxílio com as análises estatísticas; e à Agência Paulista de Tecnologia dos Agronegócios - APTA Polo Centro-Oeste, sede Jaú, pelo fornecimento das mudas de cana-de-açúcar.

\section{Referências}

ABDUL JALEEL, C.; MANIVANNAN, P.; KISHOREKUMAR, A.; SANKAR, B.; GOPI, R.; SOMASUNDARAM, R.; PANNEERSELVAM, R. Alterations in osmoregulations, antioxidant enzymes and indole alkaloid levels in Catharanthus roseus exposed to water deficit. Colloids and Surfaces B: Biointerfaces, v.59, p.150-157, 2007.

ASHRAF, M.; FOOLAD, M.R. Roles of glycine betaine and proline in improving plant abiotic stress resistance. Environmental and Experimental Botany, v.59, p.206-216, 2007.

BANZATTO, D.A.; KRONKA, S. do N. Experimentação agrícola. 4.ed. Jaboticabal: FUNEP, 2006. 237p.

BATES, L.S.; WALDREN, R.P.; TEARE, I.D. Rapid determination of free proline for water stress studies. Plant and Soil, v.39, p.205-207, 1973.

BIDÓIA, M.A.P.; SANTOS, D.M.M.; MARIN, A.; LANDELL, M.G.A.; BANZATTO, D.A.; CAZETTA, J.O. Efeito da deficiência hídrica no acúmulo de prolina livre em cana-de-açúcar, em diferentes períodos de desenvolvimento. Stab, v.24, p.6-9, 2006.

BRITO, L.K.F.L. de; SILVEIRA, J.A.G.; LIMA, L.L.F. de; TIMÓTEO, A.R. de S.; CHAGAS, R.M.; MACEDO, C.E.C. de. Alterações no perfil de frações nitrogenadas em calos de cana-de-açúcar induzidas por deficit hídrico. Pesquisa Agropecuária Brasileira, v.43, p.683-690, 2008.

CLAESSEN, M.E.C. (Org.). Manual de métodos de análise de solo. 2.ed. rev. atual. Rio de Janeiro: Embrapa-CNPS, 1997. 212p. (EMBRAPA-CNPS. Documentos, 1). 
DILLEWIJN, C. van. Botany of sugarcane. Walthham: Chronica Botanica, 1952. 371p.

EFEOĞLU, B.; EKMEKÇI, Y.; ÇIÇEK, N. Physiological responses of three maize cultivars to drought stress and recovery. South African Journal of Botany, v.75, p.34-42, 2009.

El-BASHITI, T.; HAMAMCI, H.; ÖKTEM, H.A.; YÜCEL, M. Biochemical analysis of trehalose and its metabolizing enzymes in wheat under abiotic stress conditions. Plant Science, v.169, p.47-54, 2005.

FIGUEIREDO, P. Breve história da cana-de-açúcar e do papel do Instituto Agronômico no seu estabelecimento no Brasil. In: DINARDO-MIRANDA, L.L.; VASCONCELOS, A.C.M. de; LANDELL, M.G. de A. (Ed.). Cana-de-açúcar. Campinas: Instituto Agronômico, 2008. p.31-44.

FOY, C.D.; CHANEL, R.L.; WHITE, M.C. The physiology of metal toxicity in plants. Annual Review of Plant Physiology and Plant Molecular Biology, v.29, p.511-566, 1978.

GARG, A.K.; KIM, J.K.; OWENS, T.G.; RANWALA, A.P.; DO CHOI, Y.; KOCHIAN, L.V.; WU, R.J. Trehalose accumulation in rice plants confers high tolerance levels to different abiotic stresses. Proceedings of the National Academy of Sciences of the United States of America, v.99, p.15898-15903, 2002.

GIANNAKOULA, A.; MOUSTAKAS, M.; MYLONA, P.; PAPADAKIS, I.; YUPSANIS, T. Aluminum tolerance in maize is correlated with increased levels of mineral nutrients, carbohydrates and proline, and decreased levels of lipid peroxidation and $\mathrm{Al}$ accumulation. Journal of Plant Physiology, v.165, p.385-396, 2008.

GRIEVE, C.M.; GRATTAN, S.R. Rapid assay for determination of water soluble quaternary ammonium compounds. Plant and Soil, v.70, p.303-307, 1983.

KISHOR, P.B.K.; SANGAM, S.; AMRUTHA, R.N.; LAXMI, P.S.; NAIDU, K.R.; RAO, K.R.S.S.; RAO, S.; REDDY, K.J.; THERIAPPAN, P.; SREENIVASULU, N. Regulation of proline biosynthesis, degradation, uptake and transport in higher plants: its implications in plant growth and abiotic stress tolerance. Current Science, v.88, p.424-438, 2005.

LANDELL, M.G. de A.; CAMPANA, M.P.; FIGUEIREDO, P.; SILVA, M. de A.; VASCONCELOS, A.C.M. de; BIDÓIA, M.A.P.; XAVIER, M.A.; DINARDO-MIRANDA, L.L.; PRADO, H. do; ROSSETO, R.; SANTOS, A. da S.; CAVICHIOLI, J.C.; MARTINS, A.L.M.; KANTHACK, R.A.D.; GALLO, P.B.; VEIGA FILHO, A. de A.; SILVA, D.N. da. Variedades de cana-de-açúcar para o Centro-Sul do Brasil. Campinas: Instituto Agronômico, 2004. 33p. (IAC. Boletim Técnico, 195).

MARIN, A. Influência associada do estresse hídrico e do alumínio na germinação e crescimento inicial do guandu (Cajanus cajan (L.) Millsp.). 2003. 87p. Dissertação (Mestrado) - Universidade Estadual Paulista, Jaboticabal.

MARIN, A.; SANTOS, D.M.M. dos. Interação da deficiência hídrica e da toxicidade do alumínio em guandu cultivado em hidroponia. Pesquisa Agropecuária Brasileira, v.43, p.1267-1275, 2008.

MARIN, A.; SANTOS, D.M.M. dos; BANZATTO, D.A.; CODOGNOTTO, L.M. Influência da disponibilidade hídrica e da acidez do solo no teor de prolina livre de guandu. Pesquisa Agropecuária Brasileira, v.41, p.355-358, 2006.

MAULE, R.F.; MAZZA, J.A.; MARTHAJUNIOR, G.B. Produtividade agrícola de cultivares de cana-de-açúcar em diferentes solos e épocas de colheita. Scientia Agricola, v.58, p.295-301, 2001.

NAYYAR, H. Accumulation of osmolytes and osmotic adjustment in water-stressed wheat (Triticum aestivum) and maize (Zea mays) as affected by calcium and its antagonists. Environmental and Experimental Botany, v.50, p.253-264, 2003.

NEVES, M.J.; TERENZI, H.F.; LEONE, F.A.; JORGE, J.A. Quantification of trehalose in biological samples with a conidial trehalase from the thermophilic fungus Humicola grisea var. thermoidea. World Journal of Microbiology and Biotechnology, v.10, p.17-19, 1994.

OLIVEIRA,R.A.de;DAROS, E.;ZAMBON,J.L.C.;WEBER, H.; IDO, O.T.; ZUFFELLATO-RIBAS, K.C.; KOEHLER, H.S.; SILVA, D.K.T. da. Crescimento e desenvolvimento de três cultivares de cana-de-açúcar, em cana-planta, no Estado do Paraná: taxas de crescimento. Scientia Agraria, v.5, p.87-94, 2004.

QUEIROZ, R.J.B. Quantificação da trealose e da prolina livre em cana-de-açúcar sob efeito da disponibilidade hídrica do solo. 2006. 61p. Dissertação (Mestrado) - Universidade Estadual Paulista, Jaboticabal.

RAIJ, B. van; CANTARELLA, H.; QUAGGIO, J.A.; FURLANI, A.M.C. Recomendações de adubação e calagem para o Estado de São Paulo. 2.ed. Campinas: Instituto Agronômico/Fundação IAC, 1997. 285p. (IAC. Boletim Técnico, 100).

ROSSETTO, R.; SPIRONELLO, A.; CANTARELLA, H.; QUAGGIO, J.A. Calagem para cana-de-açúcar e sua interação com a adubação potássica. Bragantia, v.63, p.105-119, 2004.

SERRAJ, R.; SINCLAIR, T.R. Osmolyte accumulation: can it really help increase crop yield under drought conditions? Plant, Cell and Environment, v.25, p.333-341, 2002.

SHARMA, P.; DUBEY, R.S. Modulation of nitrate reductase activity in rice seedlings under aluminium toxicity and water stress: role of osmolytes as enzyme protectant. Journal of Plant Physiology, v.162, p.854-862, 2005 .

SOUZA, Z.M. de; PAIXÃO, A.C.S.; PRADO, R.M.; CESARIN, L.G.; SOUZA, S.R. Manejo de palhada de cana colhida sem queima, produtividade do canavial e qualidade do caldo. Ciência Rural, v.35, p.1062-1068, 2005.

ZHANG, J.J.; HE, Z.H.; TIAN, H.; ZHU, G.H.; PENG, X.X. Identification of aluminium-responsive gene in rice cultivars with different aluminium sensitivities. Journal of Experimental Botany, v.58, p.2269-2278, 2007.

ZHENG, S.J.; YANG, J.L. Target sites of aluminum phytotoxicity. Biologia Plantarum, v.49, p.321-331, 2005.

Recebido em 15 de janeiro de 2009 e aprovado em 11 de agosto de 2009 